\title{
The Construction of Cornish Identity
}

\author{
Benjamin Schlink
}

\section{Introduction}

The "strong sense of distinct nationality [which] is still cherished in Cornwall" (White 137) came as quite a surprise to Walter White. In the 1850s, he had just come back from a journey to the south west of England, and took with him a lasting impression of the Cornishmen's revolting, anti-English character. Signs of this distinct national identity, however, have not become relics of the past but can still be discovered by today's traveller: The Cornish flag, a white cross on black ground, is almost ubiquitous in some areas and can be found on flag poles, Tshirts, or car-stickers. Traces of a different language are less frequently encountered, but appear to be even more intriguing when found on the County Hall or on tourist signs; and a cuisine which is offensively displayed as Cornish, such as Cornish cream tea with a distinctive Cornish clotted cream, Cornish ice cream, or the world-famous Cornish pasties. All things considered, even today Cornwall leaves the impression not of an English county, but a country in its own right.

This experience of an apparently deeply ingrained Cornish difference sparked my initial interest and brought about the subsequent hypothesis to which the thesis at hand is dedicated: Cornish people perceive themselves as members of a Cornish nation even though Cornwall, in legal terms, is no nation at all. Because the impression is created that Cornwall is a country although it legally is not, the question arises whether or not Cornish people describe themselves as members of a Cornish nation. Thus the first objective brings Cornish identity into focus when identity is in principle defined as "how we describe ourselves to each other" (Barker 7). Here it has to be clarified if Cornish identity is distinct from the English one and, if so, Cornish identity can be perceived as a distinct national identity. 
In isolating and analysing the elements which construct Cornish identity, this clarification can be achieved. In this fashion my analysis in chapter 3 will find that Cornish identity is both distinct from the English one and a national one; following Benedict Anderson it therefore can be claimed that Cornwall is imagined as a nation. This leads to the thesis' second objective which is to examine the way in which this Cornish nation is in fact imagined. This examination appears to be even more relevant if juxtaposed to legally acknowledged nations since Cornwall cannot refer to its legal national status but is dependent on other strategies defining it as a nation.

This thesis is partly a theoretical and partly an empirical work. The theoretical framework in which it is embedded draws on Stuart Hall's and Benedict Anderson's extensive works on identity. In more detail Hall's articles “The Question of Cultural Identity", "Who needs Identity", and "Cultural Identity and Diaspora" are the sources for a model explaining personal identity, cultural identity and culture and their mutual relation which provide a basic understanding and terminology. Benedict Anderson's Imagined Communities generally contributes to this basis in terms of defining the term "nation".

In addition, two different empirical methods will be applied. To tackle objective one, aiming on isolating and analysing the elements of Cornish identity, Mayring's content analysis as a qualitative method will be applied to empirical data. This data was collected by conducting guided interviews. Both methods were chosen mainly because they meet the two requirements which they had to fulfil: they firstly both started from an inductive perspective and were secondly applicable within this paper's time and space restrictions. Elements of Cornish identity were hence induced so as to not to distort results by foreknowledge so that the probable members of an imagined Cornish nation were given the chance to unfold their understanding of Cornish identity. Approaching the second objective, the examination of the way the Cornish nation is imagined, an analysis on the basis of Hall's five representational strategies of how a nation is imagined (cf. "Question of Cultural Identity" 293ff) will be performed.

The material which will be the basis point of reference for analysis is empirical data collected in 2013 during a stay in Truro, Cornwall. The complete material consists of recordings of four interviews two of which were transcribed and used for further analysis, selected mainly due to their prescriptive character. Hence the core theme will be the examination of Cornish identity with a focus on its national characteristics. In this way legal issues, defining the actual status of Cornwall and relationship to England, will be left aside except for superficial highlights in case they provide a better understanding of Cornish identity. Moreover historical facts presented throughout the empirical material will not be critically questioned. Lastly no all-encompassing construct of Cornish identity can be expected; rather two distinct types of it will be sketched through the analysis of empirical data. 
To start with I will provide a short survey of Cornish history with a focus on Cornish peculiarities. This short illustration aims at providing a rudimentary historical basis to the reader and has no claim for completeness. It can be stated that Cornish history begins when Celtic immigrants came to England around the sixth century AD (Tschirschky 78). After the Saxons' arrival and in the course of the subsequent centralisation of the isle, more areas came under Saxon control such as Devon in the seventh century (Tschirschky 81). However, Cornwall managed to prevent the Saxons from coming in so that Cornish kings could remain in power (Tschirschky 81). In the early tenth century, King Athelstan defined the river Tamar as the eastern border of Cornwall. Thus it was made a limited territory on which, from then on, English law was enforced (Tschirschky 81f). Cornwall is then mentioned in the Domesday Book though no differentiation is made between Cornwall and England which could mean that Cornwall was seen as part of England. However, there are counter-arguments: "[Bis] in die Tudorzeit [waren] viele Rechtsdokumente aber mit dem Geltungsbereich 'in Anglia et Cornubia' ausgestellt" (Tschirschky 82), whereby "Cornubia" stands for Cornwall. In 1337 the Duchy of Cornwall was established. In the course of this, the English King's eldest son was given the title of Duke of Cornwall and was fitted with the rights of a "quasi-sovereign" (Tschirschky 83) in granting him royal prerogatives. According to Tschirschky this can be seen as a "Mittel des priviligierten Anschlusses des Gebietes" (83) and thus differentiated Cornwall constitutionally from England.

From 1198 the Cornish Stannaries were acknowledged by the King. Cornwall was divided into several Stannaries which were areas of independent jurisdiction where not English Common law but Cornish Stannary law was in force (Tschirschky 85); during the Stannaries' heyday Stannary parliament was granted a veto over English laws concerning tin mining within Cornish territory. The next instance of Cornwall treading the boards of history is 1497 when Michael Joseph, alias "An Gof", led Cornish rebels to London to revolt against high taxation under King Henry VIII but was defeated by the King's troops (Tschirschky 86); by some this instance is judged as an indication of Cornwall not being wholly integrated into England at this time (cf. Rowse 139). The 1549 Prayer Book Rebellion can be seen as another example for Cornish independence. Cornishmen moved to Exeter to demonstrate against both the translation of the Book of Common Prayer into English which they could not understand since they spoke Cornish, and the abolition of the Latin mass (Tschirschky 87). Because the Cornish language was understood to be a Celtic one, it used to be a strong factor of differentiation between Cornwall and the rest of England until it died out in the course of the eighteenth century (Tschirschky 88). However, with its revival at the dawn of the twentieth century, attempts have been made to re-establish this distinctively Cornish institution ever since (Tschirschky 109f). In terms of the legal status of Cornwall, it was not until the 1888 County Council Act that Cornwall became a county of England. This act has remained valid until today. The last time Cornwall 
attempted to protect its "eigenen Status, den keine [andere] englische Grafschaft vorweisen konnte" (Tschirschky 90) was after the Second World War when the borders between Devon and Cornwall were to be rearranged - to the detriment of Cornwall. After all, this plan was not put into action and Cornwall prevailed over English interests (Tschirschky 90).

In order to examine wether a distinctively Cornish identity exists, and whether it takes on the form of a national identity, I have chosen the following structure: The second chapter will provide the theoretical basis, introducing Anderson's concept of "Imagined Communities" (2.1) and Hall's notion of cultural identity (2.2); subsequently the next subchapters concentrate on Hall's ideas on national cultural identity with reference to difference and representation (2.3) and introduce his five "representational strategies" through which a nation in general is imagined (2.4). The third chapter is concerned with objective one, isolating and analysing elements of Cornish identity, and applies the first method to the empirical data; thus it introduces guided interviews as a method of data collection and Mayring's content analysis as a method of data analysis (3.1). Next the data itself is outlined (3.2) and subsequently analysed (3.3). The forth chapter focuses on the second objective in applying Hall's five representational strategies on the analysis of the empirical data. However, first the fact that Cornwall is not a nation in legal terms is taken into account (4.1) which is then followed by the application of Hall's five strategies as categories of analysis $(4.2-4.6)$. This analysis will reveal four additional strategies through which a Cornish nation is imagined which were not covered by Hall. Therefore his concept will be expanded and refined to better match the Cornish case (4.7). Chapter five contains the conclusion which will discuss the given hypothesis.

\section{The Theoretical Framework}

\subsection{Anderson's "Imagined Communities"}

Generally groups within a nation which do not feel to belong to it can try to break away, be it for ethnic or other reasons (Anderson 3). However, after the Second World War only those revolutions were successful in establishing new states which were on the national, not subnational, level (Anderson 2). The obvious power of the concept of nation also figures prominently in the Cornish case. Therefore this central term needs to be defined. Anderson's main thesis is that the division of the world into nations is something artificial, not natural - that it is a construct. According to him nations are "imagined political communit[ies]" because no one within this community can know all other members (6). Besides nations are imagined as "sovereign", "as a community" and as "limited" (Anderson 7). They are imagined as sovereign since they superseded monarchy and based 
its legitimacy on freedom, not religion. Furthermore, a nation is imagined as a community because its members perceive themselves as an "us" facing a "them", binding them together in a "a deep, horizontal comradeship" (Anderson 7). Finally a nation is imagined as limited in the sense that it has boundaries and hence a fixed territory; however it is also imagined as limited with regards to the fact that not everyone is, nor can be, a member of the nation (Anderson 7). Another crucial point Anderson makes is that a nation seems to belong to the same realm like the colour of one's skin or one's gender and that it thus seems to belong to "all those things one cannot help" (Anderson 143).

\subsection{Hall and Identity}

The following will illustrate the general concept of identity concentrating on Hall's comprehension of it. In doing so his essentialist and anti-essentialist interpretation of identity will be unfolded along the levels of personal identity, cultural identity and culture. To start with, these three levels will be defined briefly.

For the purpose of this paper, it will be sufficient to define personal identity as referring to the identity of an individual; it can be allocated to a single subject. Cultural identity can be situated in the realm of collective identities; they are "those aspects of our identities which arise from our 'belonging' to distinctive ethnic, racial, linguistic, religious and, above all, national cultures" (Hall, "Question of Cultural Identity" 274). Hence it can be seen as an entity paramount to and simultaneously as a source of a subject's personal identity (Nünning 306). Culture, being the point of reference for cultural identity, is understood in a very broad sense as " $[\mathrm{t}]$ he distinctive ideas, customs, social behaviour, products, or way of life of a particular nation, society, people, or period" (OED). In this fashion the subject identifies with a specific group by means of a shared cultural identity (Hall, "Who needs Identity?" 3), whereas cultural identity draws on culture as its main source (Hall, "Question of Cultural Identity" 291).

When describing the essentialist concept of identity, having a closer look at the term essence reveals what is at the heart of this idea: the assumption that identity is "that which constitutes the being of a thing" (OED). Its historical roots can be traced back to the age of Enlightenment when man emerged "aus seiner selbstverschuldeten Unmündigkeit" (Kant 481) and became a subject first and foremost in the sense of being the agent of his own actions. On the level of personal identity, the "Enlightenment subject" was claimed to possess an unchanging, stable and essential inner core (Hall, "Question of Cultural Identity" 275). It identifies with a society of people being of the same origin to which it is bound by a "natural closure of solidarity and allegiance" (Hall, "Who needs Identity?" 2). On the collective level cultural identity can also be described as something essential but now being the essence of one people of the same origin. In this context Hall describes it as "a sort of the collective's 'one true self" which is grounded on 
the sense of sharing the same history and culture and perceived as a "stable [...] [frame] of reference and meaning" ("Diaspora" 234). However, cultural identity is not only something everyone within the society can identify with; Hall also assumes that cultural identity as the essence of a people is the one force which binds together members of the society in spite of other cultural differences ("Who needs Identity?" 3). When it comes to the level of culture, it can be seen as the system of meanings and symbols, the distinctive traditions and ideas which associate the members of a society with one cultural identity, no matter "how different the members of a [society] in terms of class, gender, race" may be (Hall, "Question of Cultural Identity" 296).

In contrast to that the anti-essentialist concept of identity is just the opposite the idea of identity as the essence of a subject and a people alike is being replaced by the notion of its construed character. Historically, in the course of the age of modernity, and especially towards the end of the twentieth century, the world became ever more complex (Hall, "Question of Cultural Identity" 274). On the level of personal identity, Hall recognised two new types of subjects successively displacing the Enlightenment subject: first the "sociological subject" which echoed the increase of complexity of the societies in so far that it is no longer described as possessing that stable core of the Enlightenment subject but that it rather is a product of the inner and the outer world (Hall, "Question of Cultural Identity" 275). To be precise, Hall still suggests that the sociological subject possesses an inner core but adds that this core was shaped by society ("Question of Cultural Identity" 275). In finally displacing it by the "post-modern subject", Hall reflects the still growing complexity of a globalised world ("Question of Cultural Identity" 276) leading to a decentred subject: it has completely lost its stable, inner centre and has not been imbued with another; instead the former centre has been displaced by "several, sometimes contradictory or unresolved, identities" (Hall, "Question of Cultural Identity" 276). On the level of cultural identity, the same process can be observed: according to Hall the subject could no more identify with the essentialist "one, shared culture" ("Diaspora" 234) but any form of identification has finally become "contingent" and is just an "articulation" and a "suturing" ("Who needs Identity?" 2) of the subject into something more important than itself, i.e. society. Therefore the understanding of cultural identity as the natural overarching object of identification of a society, its essence, needs to be altered in two ways: on the one hand it does no longer maintain this essential sameness of a people but rather bespeaks "points of deep and significant difference which constitute "what we really are" (Hall, "Diaspora" 236). Since there is no naturally given nexus between discourses of class, age, gender and race which eventually makes up one specific society, this connection has to be "articulated", has to be constructed by cultural identity (Barker 230). Thus identities have to be perceived as formed by discourses (Barker 279). On the other hand the assumption that cultural identities possess an essential history and are a society's essence 
has to be challenged: Hall stated that it is not "fixed in some essentialised past" but rather contingent on change ("Diaspora" 236). Hence cultural identity does not reflect the natural "belonging to" or identification with a distinct, essential and eternal culture but articulates "the criss-crossing discourses of race, ethnicity, nation, class, gender and age" (Barker 279). Having a closer look the level of culture, it still can be seen as the "source of cultural meaning" (Hall, "Question of Cultural Identity" 296) for a society; however, the nature of culture is changed when Hall defines it as a "system of representation" ("Question of Cultural Identity" 296). By representation Hall basically means the process of transferring meaning to items which are presented through different media (Hall and Jhally 9:55ff); thus the way and context in which, for example, a cultural artefact or a historical narration is presented can change its meaning dramatically. Cultural identities, drawing on culture as their primary source, are therefore also "constituted within, not outside representation" (Hall, "Who needs Identity?" 3).

\subsection{National Identity - A particular Form of Cultural Identity}

According to Hall, today's nation-states and their national cultures are the main source for a society's cultural identity ("Question of Cultural Identity" 291) despite the decrease of their significance due to globalisation. Within the theory depicted so far, national identities can be seen as a specific form of cultural identity insofar as they primarily highlight the belonging to national cultures. Henceforth it will be assumed that every kind of identity, be it on the personal or collective level, follows anti-essentialist principles as illustrated above. Therefore two more characteristics of and their implications for national cultural identities have to be introduced: difference and representation.

Hall claims cultural identities in general to be "organized around points of difference" ("Question of Cultural Identity" 227). Thus a nation cannot be defined without stating what it is not. Points of difference evolve around the identification with and articulation of certain discourses within social categories such as class, ethnicity, nationality, or religion (Hall, "Who needs Identity?" 3). As far as nationality is concerned, difference would translate in what Anderson calls "the irremediable particularity of [nationality's] concrete manifestations" (5): ideally a subject is a member of and identifies with only one nation-state and constructs national cultural identity by means of the difference to the rest of the nations with which it does not identify. Due to the anti-essentialist understanding of identity and the subsequent significance of representation it however follows that particular manifestations within social categories of a nation are not naturally given; on the contrary, the actual sense of those social categories has not been defined once and for all but certain representations give meaning to them (Hall, "Question of Cultural Identity" 227). 
Representations are not naturally grounded but subject to change and influence. The political implication of identity as a "production" has therefore to be taken into consideration (Hall, "Question of Cultural Identity" 227). In this manner representation encounters two problems. The first one is that of correctness (Hall and Jhally 3:55f): from a social majority's point of view, for instance the common historical experiences of a nation can be represented 'in a right way'; however, from the perspective of a minority group, it can be represented 'falsely'. If representations of common national experiences thus ignore or even expel a minority within a nation, a second problem occurs: that of inclusion and exclusion (c.f. Barker 264; Hall, "Who needs Identity?" 5). Having said that, it seems to be in the teleology of national identities not to generally exclude but instead to "help to stitch up differences into one identity" (Hall "Question of Cultural Identity" 299): the target of cultural identities in general and that of national culture in particular is to bring together the members of a society, a nation, despite their differences concerning class, gender, or race (Hall, "Question of Cultural Identity" 296) by means of a national identity representing all subjects or groups of a nation, no matter how different they may be. Despite attesting national identities a strong political significance (Hall, "Who needs Identity?" 4), Hall agrees with Anderson when repeating the latter's major claim that "national identity is an imagined community" (Hall, "Question of Cultural Identity" 293). Subsequently Hall further develops Anderson's theory by elaborating on the way nations are imagined.

\subsection{How to Imagine a Nation?}

This chapter will introduce Hall's five representational strategies through which nations are imagined: national narratives, primordial roots, invented traditions, a foundational myth, and an original folk ("Question of Cultural Identity" 293). In chapter 4 these strategies will be applied as categories of analysis, examining empirical data in terms of how the interviewees imagine a 'Cornish nation'. Firstly, narratives of a nation are crucial representations through which national identities are constructed ("Question of Cultural Identity" 293):

These provide a set of stories, images, landscapes [...] historical events, national symbols and rituals which stand for, or represent, the shared experiences, sorrows, and triumphs and disasters which give meaning to the nation. As members of such an 'imaginative community', we see ourselves in our mind's eye sharing in this narrative. ("Question of Cultural Identity" 293)

Secondly the representation of a national identity as primordial and eternal is of significance: its major traits today appear to be in line with those of the past despite the challenges of history because they are ingrained in a nation and constitute its very essence. Moreover this past can be recurred to if the nation has 'alienated' 
itself from its essential identity in order to restore it. Representations of national identities therefore highlight "origins, continuity, tradition and timelessness" ("Question of Cultural Identity" 294).

Thirdly Hall draws on Hobsbawm's and Ranger's concept of the invention of tradition ("Question of Cultural Identity" 294) which they define as

[t]raditions which appear [...] to be old [but are] often quite recent in origin and sometimes invented. [They are] a set of practices, [...] of a ritual or symbolic nature which seek to inculcate certain values and norms of behaviours by repetition which automatically implies continuity with a suitable historical past. (1)

Furthermore, a subtype of the first representational strategy, the narratives of a nation, is supposed to be a very crucial strategy: the foundational myth ("Question of Cultural Identity" 294f). It can be defined as the story of origin of "the nation, the people and their national character" which is so ancient that "they are lost in the mists of, not 'real', but 'mythic' time ("Question of Cultural Identity" 294f). In addition, Hall claims that "disenfranchised people" can utilise foundational myths in order to create a new nation in its own right: it provides them with a historical representation of that cultural national identity which they had possessed before they were colonised and which was oppressed subsequently ("Question of Cultural Identity" 295). National identity is finally based on the notion of "a pure, original people or "folk" despite the fact that in reality hardly any nation can be found which actually derives from one folk in particular ("Question of Cultural Identity" 295).

\section{Cornwall's Reality - Introducing and Analysing Empirical Data}

The following chapter is concerned with the first objective of this thesis. Thus it attempts to isolate and analyse elements constructing Cornish identity in order to find out whether Cornish people feel to belong to different "ethnic, racial, linguistic, religious and [...] national cultures" (Hall, "Question of Cultural Identity" 274) than England. In this fashion the methods of data collection and analysis are presented (3.1), followed by an introduction of the data (3.2) and the actual analysis (3.3).

\subsection{Methods}

The aim of both data collection and analysis was to be as open and non-partisan as possible. As a result the interviewees should be enabled to unfold their understanding of Cornish identity while not being manipulated by the interviewer's 
foreknowledge or biased questioning. Thus a qualitative approach to data collection and an inductive analysing procedure were necessary.

As far as data collection is concerned, a semi-structured guided interview was conducted. The interview guideline based on both Hall's five categories through which a nation is imagined and general foreknowledge mainly gained through Tschirschky's "Die Erfindung der keltischen Nation Cornwalls"; however, it was organised in such a way that it did not exclude possible deviations or refinements. The applied interview technique attempted to echo this intention by implementing Merton's criteria of range and depth', generally suggesting that one of the main aims is "to uncover a diversity of relevant responses, whether or not these have been anticipated by the inquirer" (Merton 12). According to the criteria of range, the interviews followed the subsequent two elements: on the one hand they started with unstructured questions in order to let the interviewee decide whatever holds significance for him or her (Merton 54). On the other hand changes from one topic to another or the introduction of new topics were the task of the interviewee so that he or she could illustrate the interconnections between different elements and determine the sequence of the interview (Merton 55). The criteria of depth especially aims on yielding emotional responses because those are seen to be central to the interviewee (cf. Merton 97). Thus in using the method of a guided interview in combination with Merton's criteria of range and depth, the target of being both open and non-partisan could have been achieved in the stage of data collection.

As a method of data analysis, Mayring's qualitative content analysis was the means of choice for several reasons. One was that it is considered to be an inductive approach. With the main aim of openness and impartiality, such an inductive analysis seems to be compulsory. Having said that, Mayring's content analysis appears to be a necessary compromise between an open approach towards the collected data and the time required for its analysis: procedures such as Rosenthal's 'Interpretative Sozialforschung' offer the advantage of a maximum of openness and interpret only from a subject's point of view (cf. Rosenthal 18ff); however favourable this method may be in terms of impartiality, it needs a considerably bigger amount of time compared to Mayring's approach. Due to the limited time frame of the thesis at hand, Mayring's procedure thus appeared to be the appropriate means of analysis. Furthermore content analysis follows a what Mayring calls "systematische[s] Vorgehen" because it is "regelgeleitet $[\ldots]$ und theoriegeleitet" (12). This is claimed to be generally beneficial because it is not an arbitrary

1 Although Merton describes these criteria in terms of the application of focused interviews, they can nevertheless also be applied in semi-structured guided interviews. The only difference would be the point of reference that the interview questions try to aim at: in the case of focused interviews, it is the stimulus situation the interviewee was being exposed to before; in the case of the guided interview, it is the general opinion, feelings and convictions to the topic in question. 
interpretation of material but analysis becomes replicable if provided that the same rules and theory are utilised (Mayring 12).

\subsection{Introducing the data}

The following will introduce the collected data in accordance with Mayring's suggestions (cf. 54). Firstly the material is presented, followed by a description of the stage of data collection, from first contact to the interview situation. Thirdly the formal characteristics are discussed, followed by a theoretical grounding of the questions addressed to the material. Subsequently the technique of analysis will briefly be explained and the classification of the analysis' results will finally be categorised.

\section{The Material}

The material is derived from interviews which were conducted in May and June 2013 in Cornwall. In total four interviews were carried out from which two were selected for further analysis. The reason for focusing on these in particular is twofold: they appeared to be descriptive in terms of this thesis' interest as the interviewees talked without requiring too much input from the interviewer, and Cornish identity appeared to be an essential element in their lives. Furthermore, a selection had to be made simply due to the restricted time frame. For the analysis interview parts were preferred which could provide answers referring to the question of the elements finally creating Cornish identity. The first interview partner was Eve Morris* who has been an active member of the pro-Cornwall party Mebyon Kernow (MK) since 1999 and was a town councillor for this party until 2013. The second interview partner was Keneder Bligh* who has been actively engaged in the Cornish Language Partnership until 2011, an institution trying to strengthen the role of the Cornish language in Cornwall. Since then he generally tried to reinforce Cornish within school education. Both of them were selected mainly because of the roles they occupy.

\section{Data Collection Stage}

In order to find suitable interview partners, the internet was searched for Cornish organisations which attempt to strengthen Cornwall's political, cultural, or economic situation. Suitable means that the prospective interviewees should relate to a Cornish identity and try to support the Cornish cultural identity by means of the work they do for these Cornish organisations. In a first step those persons were contacted using standardised e-mails including the content and aim of the study and the enquiry for a conversation. In a second step the prospective interviewees

\footnotetext{
* The interviewees' names and occupations are anonymised.
} 
were called in order to provide them with further information and to set time and place for the interview in case of approval.

In Cornwall the first interview was conducted with Eve Morris. It took place in the lobby of Cornwall County Hall and lasted for 45 minutes. In a later reflection she "appeared very friendly and interested in the topic" and the atmosphere during the conversation was described as "quite natural and relaxed". The second interview with Keneder Bligh took place in a meeting room at Cornwall County Hall and lasted for about 90 minutes. Although being "welcoming and friendly" when first meeting him in person, during the interview he appeared to be "a bit distracted or overextended because it sometimes took him long to actually finish a sentence".

\section{Formal Characteristics}

As far as formal characteristics of the material are concerned, the interviews were recorded and subsequently transcribed in accordance to Rosenthal's transcription code (95):

\begin{tabular}{|ll|}
\hline (4) & kurzes Absetzen \\
Ja: & Dauer der Pause in Sekunden \\
((lachend)) & Dehnung eines Vokals \\
nein & Kommentar der Transkribierenden \\
NEIN & betont \\
viel- & laut \\
(sagte er) & Abbruch eines Wortes oder einer Äußerung \\
Ja=ja & unsichere Transkription \\
ja so war & schneller Anschluss \\
nein ich & gleichzeitiges Sprechen ab „SO“ \\
\hline
\end{tabular}

Fig. 1: Rosenthal's transcription code

\section{Theoretical Grounding}

It has been stated above that one advantage of Mayring's content analysis is the fact that it is theory-driven whilst still formulating categories inductively. In the case under consideration, the empirical material consists of statements made by two official representatives of a specific form of cultural identity. As already illustrated, Stuart Hall claims that cultural identities do not refer to a group's essential characteristics but that they are rather an articulation of different discourses which only appear to be primordial. Thus he demonstrated that national identities are generally imagined by means of five different representational strategies. Moreover he claimed identities in general to be "organized around points of difference" ("Question of Cultural Identity" 227). Lastly he also states that cultural identities in general refer to culture as a point of identification. Embedded in this theory the 
following leading question to the material arises: What are the general elements that make up Cornish identity?

It is important to note once more that, in the following analysis, the provided theory only supported the process of finding suitable questions to the material in order to identify elements of Cornish identity. The analysis itself was conducted inductively so that the condition of being as open and non-partisan as possible was not harmed.

\section{Technique of Analysis}

The following analysis will use the qualitative technique of "summary", one possible content analytical procedure. Here Mayring suggests to proceed in five steps: forming paraphrases, definition of the level of abstraction, generalisation, first reduction, and second reduction. In forming paraphrases, superfluous information is excluded from further analysis in removing "nicht (oder wenig) inhaltstragende Textbestandteile wie ausschmückende, wiederholende [...] Wendungen” (Mayring 62). Moreover the text is transformed into a grammatical short version (Mayring 62). After that, the definition of the abstraction level is the point of orientation for the following steps (Mayring 62); in the analysis of Cornish identity, it was defined as "general, though case-specific statements about Cornish culture and assumptions about Cornish identity". Paraphrases of step one being below the defined level of abstraction are then generalised onto this level so that the new, generalised statements imply the old paraphrase (Mayring 62). In the subsequent first reduction those generalised paraphrases are removed which are meaningless or redundant in terms of the research question. (Mayring 62). In a final second reduction, paraphrases with similar meanings are condensed to one paraphrase (Mayring 62).

\section{Classification of Results}

Usually Mayring's content analysis demands more material in order to aggregate different cases to be able to induce more universal statements about the subject of research (cf. 71). However, the restrictions of this study do not allow such an approach. The two interviews in consideration, i.e. that of Eve Morris and Keneder Bligh, are therefore perceived as representations of two different descriptive types of Cornish identity. Thus a descriptive type can be defined as the summary of individual criterial features (cf. Rosenthal 75). This entails that other types of Cornish identity, consisting of other features, can exist which differ from the two illustrated ones.

\subsection{Data Analysis}

The analysis is split into two parts, each of which describes one type of Cornish identity. The two interview transcripts will be used as the basis of analysis. Part 1 
will explore Eve Morris' construct of Cornish identity, part 2 that of Keneder Bligh.

\subsubsection{Eve Morris' Construct of Cornish Identity}

The main point Morris makes about her perception of Cornish identity is that she "happily" considers herself as Cornish and British, but by no means as English. This notion can be seen as lying at the very heart of her Cornish identity. From this conviction several reasons evolve explaining at the same time why Cornish identity is different from the English one, why Cornwall thus is different from England, and lastly which elements create Cornish identity. The following illustration depicts her general concept of Cornish identity²:

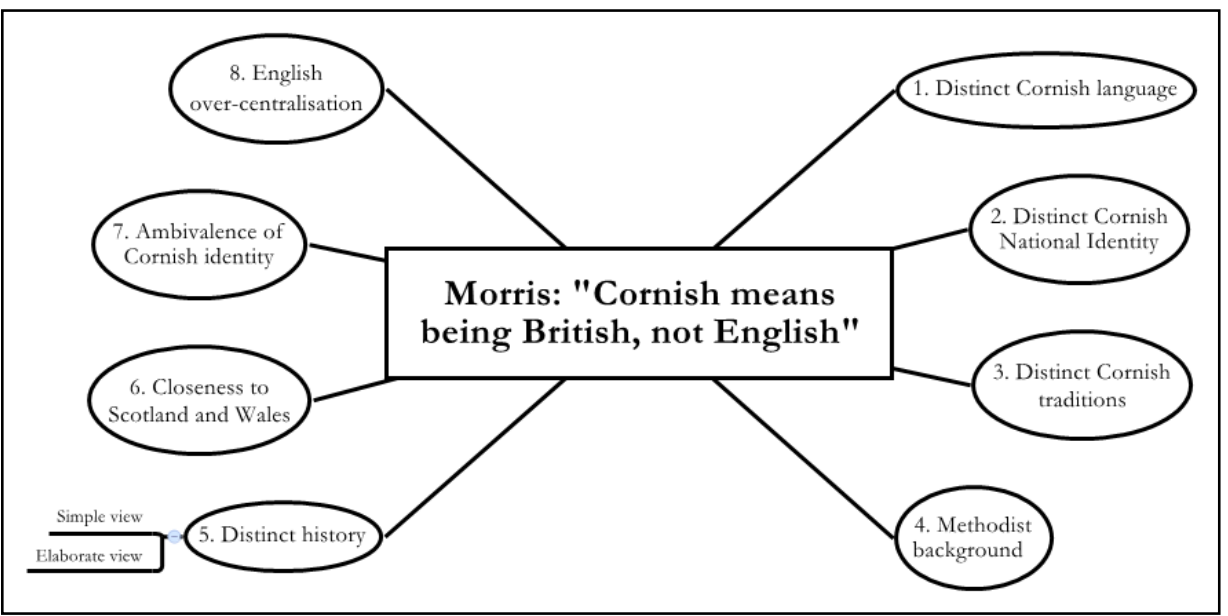

Fig. 2: The Construct of Eve Morris' Cornish Identity

According to Morris, the Cornish language is the "number one thing" for Cornish identity. In this way it ensured continuity within Cornwall before it actually died out in the nineteenth century. The death of the language was followed by an attempt to revive it in the beginning of the twentieth century in order to keep alive Cornish traditions of the past. Moreover the fact is stressed that Cornish was not spoken outside its borders.

Next the claim that Cornish identity is one in its own right and not positively related to England is underpinned by claiming that it is a "distinct national identity". The fact that Cornwall possesses its own language provides the very basis of this claim and justifies that it is not merely seen as a region or county of England but as a nation in itself. Furthermore, Cornwall has its own national origins which

2 For the matter of simplicity, the term Cornish identity and Cornish national identity will subsequently be used to refer to that type of Cornish identity which Eve Morris represents. 
are different to the English ones: they descend from the nation of people which originally existed in Cornwall. Lastly, Cornwall is the same as the rest of all nations worldwide as far as self-identification is concerned: it is just about members identifying with their nation which actually produces it. If members of Cornwall thus identify with a Cornish nation, this nation comes into existence.

The next distinctive trait of Cornishness Morris mentions are Cornish traditions. First of all they are built around the Cornish language and derive from it. One instance is provided by hurling, a very rough sport which was and still is played exclusively in Cornwall. A second example provides Cornish rules wrestling. Although wrestling in general is not typically Cornish, the very fact that the rules are close to those of Breton and not compatible with Devon ones makes it a cultural signifier. Finally Cornwall's Methodist background adds to the Cornish difference because it is perceived as a very strong tradition. As a proof of this, Morris states that the percentage of Methodists in Cornwall is, if not the highest, than at least amongst the highest of the country.

Yet another point of difference can be identified when focusing on Morris' representation of Cornish history since the settlement of the Anglo-Saxons. In general it illustrates the origins of Cornwall and identifies the Cornish as a distinct people with a distinct national origin. Thus it provides an alternative argument for the fact that Cornish identity is an explicitly national one. When making remarks on history in more detail, Morris recognises two different views on it: a simple and an elaborate one. The simple view basically claims that the English descend from the Saxons and the Cornish from the Celts. With the Saxons arriving on the island, they are said to have massacred the Celts and forced those which survived to become English. As an historical instance, the rebellion of 1497 can be interpreted as one driven by the Cornish nation while pursuing aims grounding in the protection of Cornish national identity. The elaborate view on history suggests that the impact of the Saxon invasion was in fact less than "told in these simplistic old tales". The Saxons did not massacre all Celts when arriving on the island but rather became the new ruling class; thus the Celts were ruled, not massacred, by the Anglo-Saxon lords. The fact that the Celtic people and traditions actually did not die out entails that it still exists today in all people of Britain. Within the elaborate view on history, the rebellion of 1497 should therefore not be interpreted as a national rebellion of the Cornish nation. Having said that, Morris is in favour of the elaborate view on history and rejects the simplistic one as depicted above.

As strongly as Morris argues for Cornwall being different from England, as fiercely does she support the equality between Cornwall, Wales and Scotland. With reference to the Welsh identity, she claims that it is fully acknowledged as being different from the English, and that this is why Wales is perceived as a country different from England. The fact that Wales is seen as an integral part of Great Britain and as a country at the same time provides its necessary "bit of otherness", providing the grounds for an own Welsh national identity. Morries identi- 
fies the reason for that in two things: firstly the fact that Wales maintained its own language facilitates its perception as a country in its own right; secondly Welsh people can look back to distinct national origins, descending from the nation of people which originally could be found in Wales and which kept certain traditions alive until today. Although the Scottish identity and Scottish nation is as well acknowledged as being definitively distinctive from the English one, Morris here shifts the focus to what it actually lacks although it is seen as different: unlike Welsh, Scots Gaelic is not widely spoken within Scotland and can hence not be identified as a reason for the otherness of a Scottish identity and the Scottish nation. Neither are Scottish traditions perceived as an adequate basis which could justify Scotland's special status: many of them are shared by English and Scots alike.

Morris then claims that Cornwall is equal to Wales and Scotland for a variety of reasons. First of all Cornwall possesses an own national identity, with the only difference that Scotland and Wales are actually perceived as nations whereas Cornwall is not. Furthermore Cornwall and Scotland are particularly similar in that the cultural distinctiveness from Scotland and England has the same basis: Scots Gaelic and Cornish alike are not widely spoken in the respective countries. The only element differentiating Cornwall from Scotland is the fact that the latter has more and stronger political institutions. But then again, so she argues, Cornwall could also have these institutions and would be as legitimised of being a nation as Scotland.

After having made the claim that Cornwall is equal to Scotland and Wales and not to England, the question arises why Cornwall is actually a part of England. Historically Morris argues that Cornwall used to be separate from England but was incorporated at a very early time. She claims that Cornish identity therefore appears weak since Cornwall has been perceived as being internal to it for a long time. The over-centralisation of the United Kingdom is again another reason, bringing in its wake the problem that the contradiction between English and British generally is not widely recognised. In terms of political power, it moreover deprives Cornwall of the possibility to make decisions of local importance locally. This is why Morris argues for Cornwall to become a devolved part of Great Britain and to be granted an own assembly equal to the Scottish parliament in order to make decisions according to the principle of subsidiarity.

With reference to the strength of Cornish identity, Morris finally identifies a certain ambivalence. In this fashion some people see themselves as Cornish and English at the very same time: in one moment they would cheer for their Cornish rugby team and in the next they support the English national football team with the same tremendous spirit. On the one hand this ambivalence, the fact that people living in Cornwall can possess a strong sense of being Cornish and English at the same time, is supposed to be something which makes the Cornish identity "unique". On the other hand Morris later on suggests that it is actually not as 
unique as she thought because identity is always a very personal thing. However, for her the notion of being Cornish is what she is about, is "at the heart" of all the things which constitute her identity.

Coming back to the key question asking about the elements which define Cornish identity, Morris' construction of it is generally created by the notion of being different to England and equal to Scotland and Wales; basically two lines of argumentation surfaced: the 'same-degree-of-otherness' argument which is underpinned by the 'Celtic-Cornish-culture' argument. Morris denies the "simplistic view on history" and she thus does not reduce the link between Cornwall, Scotland and Wales primarily to their common Celtic origin. Morris rather advocates the "elaborate view on history" where the Celts and their traditions continued to live across the whole of Britain after Saxon invasion. In taking away the underlying connecting idea of Celticism she significantly weakens the bond between Cornwall, Wales and Scotland. However, she re-establishes a perception of them as being equal again, now not primarily on racial grounds but in terms of having the same degree of otherness to England: By claiming the distinctiveness of the Cornish language, culture, history, and subsequently the distinctiveness of the Cornish national identity, Morris primarily aims at constructing that necessary "bit of otherness" which enabled Wales and Scotland to become nations. Thus the two role models are not seen as Celtic countries but only as countries within the United Kingdom and other than England. Because their degree of otherness is equal to that of Cornwall, the latter also qualifies for being a nation in its own right. This equality argument is then enforced by cultural implications. For instance, Morris claims that Cornish rules wrestling is not compatible to Devon but to Brittany rules wrestling. If Devon is seen, pas pro toto, as a part of England and Brittany along the same line as a part of the Celtic nations, Morris constructs a cultural link between Cornwall and a Celtic country while simultaneously denying a compatibility between Cornwall and England. Wrestling could also be seen as a representative of the culture of the respective countries in general. Following this thought it would imply that because Cornwall's culture corresponds to Celtic cultures and not to English, Cornwall and Cornish identity itself must be different from England and comparable to that of the Celtic nations. Therefore the 'same-degree-ofotherness' argument is implicitly supported by the 'Celtic-Cornish-culture' argument.

\subsubsection{Keneder Bligh's Construct of Cornish Identity}

At first sight, the construction of Bligh's Cornish identity equals that of Morris. For Bligh the difference between Cornwall and England is also situated at the very centre of Cornish identity. However, the way that difference is constructed is altered. On a first level, two primary elements of Cornish identity vividly depict that difference: Cornish language as being one "in its own right" and that "an essential part of being Cornish is being Celtic". On a second step this leads to two 
secondary elements of Cornishness: a distinctive Cornish culture and Cornish history. On the third level, two tertiary elements of Cornish identity can be identified supporting the notion of difference between England and Cornwall: the economic situation and the organisation of social life. Finally the English are perceived as the centre of an Anglo-centric United Kingdom. As will be shown below, this produces two meta-elements of Cornish identity which describe the overall feeling of Cornishness: that of being suppressed by England within the United Kingdom and that of hence being a minority within its realms. The illustration below summarises Bligh's concept of Cornish identity3:

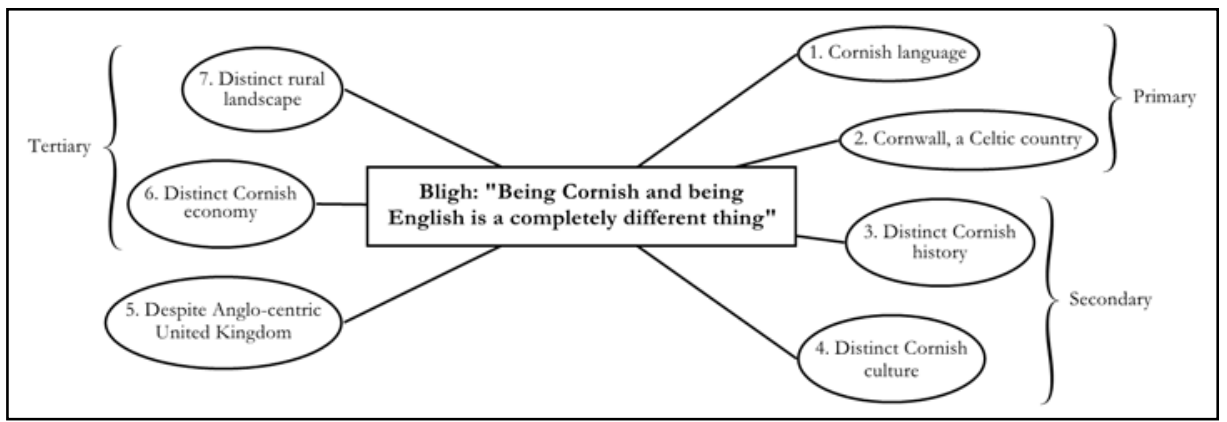

Fig. 3: The Construct of Keneder Bligh's Cornish Identity

The first primary element of Cornish identity is the Cornish language. For Bligh it is "a key to it all" in terms of understanding Cornish identity and Cornwall's difference to England. For him it neither matters that the actual speaker community is very limited nor that Cornish is a revived language. On the contrary, the fact that Jenner revived it in 1904 is seen in a positive way since it makes the language special. It is therefore perceived as being at the very core of Cornish identity because all other primary characteristics of Cornishness are derived from it. The first and simultaneously most important nexus is that between the Cornish language and Cornwall being a Celtic country: In presuming that "Celtic" can only refer to "those geographical area[s] where a Celtic language is spoken", the fact that Cornish as a Celtic language is spoken in Cornwall defines it as being Celtic.

Secondly the Cornish language carries plenty of "cultural implications and hooks" as well. Plays and literature in particular can only be properly understood through the language. In addition, Cornish linguistically defines the eastern border with England as lying east of the river Tamar: When comparing the place names of Cornwall and Devon, it figures very prominently that in Cornwall around $75 \%$ of the place names are of Cornish origin. In Devon, situated on the eastern side of

3 For the matter of simplicity, the terms 'Cornish identity' and 'Cornish national identity' will subsequently be used in order to refer to that type of Cornish identity represented by Keneder Bligh. 
the Tamar, Cornish place names can hardly be found at all. The linguistic boundary can thus be seen as the geographical limit of the territory of Cornish identity. On the grounds of an existing Cornish language and the fact that Cornwall has its own history and culture, Bligh finally claims that it is not a county or region within England but a nation such as England and within the United Kingdom.

The second primary element of Cornish identity is that Cornwall is a Celtic country. Next to the fact that Cornish is a Celtic language, both being necessary and sufficient condition making Cornwall a Celtic country, two more characteristics are introduced by Bligh which underpin Cornwall's Celtic status: certain aspects of Cornish culture and the history of Cornwall. As far as culture is concerned, several characteristics can be identified which support Cornwall's Celticness. Within the realms of material culture, Celtic crosses and carvings can be found all over Cornwall and are mainly a sign of Celticism since they can also be found in other Celtic countries such as Brittany and Scotland. Moreover Cornwall possesses its own form of bagpipes which are identified as part of the Celtic culture. They are distinctively Cornish due to their construction and unique sound which is described as "raw and rough". As part of Celtic cultural institutions, the Gorseth, a gathering of bards conducting a ceremony which is done only through the medium of Cornish, figures very prominently. Despite the fact that it was reconstructed in Cornwall in 1928 on the basis of a reconstruction of the Welsh (1840s) and the Breton (1899) Gorseth, it still is very important.

Cornish literature from medieval times can also be identified to reflect Cornish Celtic roots to a certain extent. In particular Bligh mentions the Ordinalia, a Cornish mythical play consisting of three different parts, and Beunans Meriasek, another Cornish medieval play written by Adolphos Tom and depicting the life of Saint Meriasek. They are generally seen as being a part of Cornwall's Celtic heritage because they are written in Cornish. Also certain elements of the stories illustrate its Celtic character, for instance a story in Beunans Meriasek in which the number of three, referring to the trinity of God, son and Holy Ghost, is often mentioned. According to Bligh, that number is not to be found in the Bible with reference to the concept of trinity but is the sacred number of the Celts.

Cornwall's history in general is also taken into consideration when claiming Cornwall to be a Celtic country. Bligh presupposed that England has persecuted the Celts and Celtic languages for thousands of years and fought against the Celtic nations for the same amount of time. In this period of history, to which no exact dates are given but just the time reference "for thousands of years" is attached to, Cornwall is positioned on the side of the persecuted Celts. The instance which politically established Cornwall as Celtic can be traced back to 1904 when Cornwall was admitted into the Celtic Congress and became one of today's six Celtic nations through the agitation of Henry Jenner. History even serves another end: it is a means of representing the closeness between Cornwall and its Celtic sister countries and thus underpins its Celtic character once more. In particular Brittany 
as Cornwall's sister country is mentioned frequently. Quite bluntly Bligh explains their close relation by seeing them both as Celtic countries. Both countries have a different history, culture and language compared to that of France and England respectively and were subsequently suppressed by the one or the other. That feeling of being suppressed is one which both Celtic countries have suffered from and which brings them closer together. In the past the link between Cornwall and Brittany was even stronger than today: not only did they share Kings and a similar flag but also the "ownership of King Arthur", as Bligh puts it. Besides they would have sent members to each other's Gorseths.

After having identified the Cornish language and its Celtic character as two primary elements of Cornish identity, secondary elements can be identified which serve the same ends as the primary ones: producing the notion of difference of Cornwall in comparison to England. Thus Cornish culture and Cornish history will be discussed in more detail. When having a closer look on Cornish history, Cornwall was in opposition to England from early times onwards. This explains that when the Danes and Vikings invaded the island the Cornish would side with them and fight against the Saxons. The Saxons in turn are clearly identified as the people which inhabit England today. Next Cornwall became a Duchy in the year 1337. This can be seen as an important event in Cornish history since from this year onwards, a separate legal system was established in Cornwall and the Duke of Cornwall, the eldest son of the King of England, was appointed as head of state in this territory - and not the King of England directly.

The story of An Gof figures prominently as he led the 1497 rebellion of Cornish people against the Crown of England due to the English suspending Stannary parliament. Before the rebellion the Cornish were granted an own parliament because of their economic importance for England: It was in Cornwall that the tin was mined which was vital for the English industry. Because of the suspension of the Stannary parliament, An Gof and Thomas Flamank, together with their army, headed to London but were "slaughtered by English troops". According to Bligh, this was one event where Cornwall "was on the wrong side".

A further important historical event took place in 1549 in the course of the Prayer Book Rebellion to which Bligh refers to as the "Cornish Holocaust". With England becoming Protestant, Bibles were printed in English and the mass was read from this point onwards in English only. Because the Cornish did not speak any English, they could not understand mass anymore. Therefore they gathered an army and attempted a rebellion which was quickly defeated by English troops. In the aftermath of this rebellion, horrid events are said to have happened: Not only did English troops hunt and kill deserters from the battle field but they also invaded into Cornwall and killed around $20 \%$ of the male population. Moreover the links to the Cornish sister country Brittany were cut because it was still a Catholic country. Next Glasnik college was burned down which used to be the centre of education in Cornwall. According to Bligh, it could have rivalled Oxford and 
Cambridge in present days if they "had left it alone". Last but not least this rebellion meant the end of the Cornish language because no word of it was to be spoken in churches anymore. What is more, the story of what Bligh calls the "Cornish Holocaust" is described as a suppressed bit of history nowadays: no one is actually allowed to know it.

The last important event in Cornish history Bligh mentions is the story of the English Civil War of the 1640s. For Bligh this is yet again another case of Cornwall being on the wrong side since in the course of the war between the supporters of monarchy and those of parliamentarism, Cornwall sided with the royalists and was defeated by the parliamentary army. Cornwall and other Celtic countries still suffer from this today because this is why "London makes the rules". In summary it can be said that in neither of the depicted events, Cornwall was on the side of England but rather in opposition to it. Because they used to be on the wrong side more than once, they were beaten by England. The representation of Cornish history thus seems to transport two implications: firstly again the general closeness to Cornwall's Celtic sister countries which seems to underlie Cornish history and secondly the fact that it has been suppressed by England from early times onwards.

The parts of Cornish culture which have not already been discussed above in terms of their Celtic value illustrate another secondary element which Cornish identity refers to in order to claim its difference from England. Differences in sports and in the legal system will be examined more thoroughly now. As far as sports are concerned, Bligh states that three different kinds are very important in Cornwall: rugby, gig rowing and hurling. To start out with, rugby is a crucial expression of Cornish cultural difference and distinctiveness. Bligh claims that the English football culture is completely alien to Cornwall and that Cornish people do not support the English football team. In order to strengthen his point, he claims that the Cornish are bad at football in general and that it is rubbish for him. Rugby is the sport which is played and widely supported in Cornwall such as it is in Wales, too. This is what the Cornish are really good at. In fact they do so well at rugby that the Cornish Pirates qualified for the English premiership. But the English would not be the English if they did not try to spoon-feed the Cornish in one way or another: because they claimed the Pirate's rugby stadium to be too small, they were not allowed into the English premiership in spite of their formally correct qualification.

Two other sports are claimed to be not only specifically Cornish but actually to be Cornish national sports: gig rowing and wrestling. Both of them are distinctive national Cornish sports because - "like baseball in America" - they are virtually non-existent outside of Cornwall. In spite of their importance for Cornwall, Bligh states that they do not get the amount of representation in television they actually deserve. In sum, Cornish sports thus underpin the distinctive culture of 
Cornwall and define it as a national one. Moreover, sports seem once again to express a suppression of Cornwall by England.

A further cultural difference between England and Cornwall can be identified in the Cornish legal system. This difference historically goes back to Cornwall being a Duchy and possessing its own Stannary parliament with its own set of laws, called Stannary law. For instance, flotsam in England belongs to the Queen while in Cornwall it belongs to the Duke of Cornwall. With the Charter of Pardon in 1508, Cornwall was given the right to pass its own laws. This right has never been repealed so it is de jure still valid according to English law. Along the same lines Stannary law is still valid today, too. Bligh proves that this is actually the case through a meaningful example:

Nirex, which used to be an English state-run company for dumping nuclear waste, started investigations in Cornwall for a disposal site in the 1970s. Cornishmen became aware of that and did not appreciate the idea of having nuclear waste dumped in their home ground. But instead of merely mourning about the situation, a group of people actually decided to do something against it. Claiming to be tinners, they dug trenches across the roads to stop Nirex' lorries from further investigation. These "tinners" were of course arrested and put into prison almost immediately. However, the Nirexians failed to reckon with the tinners' attorney. He claimed Stannary law according to which tin miners may dig trenches when they investigate for future tin mines wherever they want. Nirex' lawyers found that to be ridiculous but the judge did not. He actually told them to "go back and do their homework", and he thus released the tinners who were actually no tinners at all but shareholders in a local company. Being free again they started to dig more trenches in their eager attempt to find tin deposits. In doing so they established a system of trenches obstructing Nirex lorries in their investigations once and for all.

This instance does not merely prove the validity of Stannary law in present times. This story rather entails more implications which can help to understand Cornish identity as a whole. On the one hand it amplifies the argument of Cornish difference in the realm of legal difference because this law is still applicable today. On the other hand it reveals something about the way Cornish people see themselves: Nirex, as a state-run company of England, could be seen as the English suppressor which this time was defeated by Cornishmen's wits. Throughout history it was usually Cornwall that was "on the wrong side" and defeated; this time, however, they outwitted England and repelled their attack. Nevertheless, this reasoning yet again throws light on the default mode of the Cornish-English relationship: instances when Cornwall strikes back and wins are the exception; more often than not it is defeated and suppressed by English force. Although Bligh only mentions the supremacy of the English language over the Celtic languages, his depiction of Cornish history and culture implicitly entail that not only the English language, but England in general is seen as superior. 
It is this underlying notion of English superiority which is attacked by Bligh several times during the interview. It is to say that he seldom openly attempted to undermine England's assumed superior position but that he did so mainly through devaluing certain elements of English (high) culture through which its superiority seems to be expressed. At least three instances of hidden attacks against English supremacy can be identified.

Bligh firstly insinuates England to rather arrogantly believe that all the world speaks English and that therefore English people have no reason to learn foreign languages. However, so he concludes, the world speaks American, not British English which is why their arrogant attitude cannot be justified. He again devalues the English language in juxtaposing it to Cornish: He had to learn English when he was young and uses it nowadays because the majority does. In opposition to that, he consciously decided to learn Cornish as an adult. For him, English is only a "noise" coming out of someone's mouth in order to communicate; Cornish as a language in its own right appears to be far more to him: it does not only serve the ends of communication but carries the core of Cornish identity. Although he does not explicitly describe Cornish as a beautiful language as opposed to "the Noise", he implicitly establishes a hierarchy in which Cornish signifies to be the more valuable language of his heart and English appears to be the less valuable, rather pragmatic language of his mind. But his final strike against the English suppressor does not directly aim at the language itself. Rather, Bligh holds the whole of English high culture, the whole of English arrogance and superiority at gunpoint when comparing Shakespeare's Macbeth to Adolphos Tom's Beunans Meriasek: when Cornish Adolphos was able to write his play in seven-syllable rhymes from the first line to the last, Shakespeare tried to do the same when writing the speech of Macbeth - Bligh does not elaborate which speech is meant - but failed because he was not competent enough to maintain it for very long. Hence Shakespeare could only write what Bligh calls "gibberish". By this, he - at least in his imagination completely degrades English high culture. In "proving" English superiority to be unjustified, the former hierarchy between England and Cornwall is inverted for a moment; however, this statement once more reveals what is Cornish fantasy and actual reality: the attack on English culture seems to be an attempt to take away the legitimacy of English superiority and subsequent suppression and to present an instance when Cornwall is not defeated by the English as illustrated throughout history. But in reality English superiority still lurks beneath the surface through the eyes of a Cornishman.

Finally, the tertiary elements of Cornish identity by means of which Cornish difference from England is manifested are the economic situation and the general organisation of social life. As far as economy is concerned, from Bligh's hopes for Cornwall's future his views on its present situation can be deduced. Thus Cornwall neither offers any job nor higher education opportunities for its youth. Too little business is settled in Cornwall in order to provide sufficient positions for the 
younger generation, and with not having an independent university within the borders of Cornwall, none of those businesses can really be established there. As a consequence at least the best young Cornishmen and Cornishwomen move to London to make a living there which leads to a "brain drain" in Cornwall. In this fashion, London is seen as Cornwall's opposite pole in terms of education and economy, being the thriving, successful and thus once again the superior centre of England.

The organisation of social life is another instance of both Cornish distinctiveness and English superiority. According to Bligh, Cornwall is only "a spread of small towns" and has a rural character. By way of contrast, England with its urban character is not comparable to Cornwall at all. The subsequent problem evolving out of this difference lies in the realm of power and politics: because of the Anglocentric character of the United Kingdom, London makes the rules. But those rules are urban-shaped solutions which simply do not fit rural Cornwall and thus create more problems than they actually solve. Hence, in not acknowledging the different socio-geographical character of Cornwall, England changes it to the worse and suppresses Cornish attempts at improving its situation.

In eventually coming back to the initial question asking for the elements which compose Cornish identity, it can be summarised that at the obvious core of it lies the Cornish-English relationship. Bligh tries to point out time and time again that this relation is one of difference, not equality. This difference is primarily produced by relating Cornishness to the distinctive Cornish language and its Celtic origin, secondary by presupposing a culture and history which marks Cornish otherness, and tertiary by juxtaposing the economic, educational and organisational situation in Cornwall to the one in England. On a next level the analysis revealed two meta-elements of Cornish identity: the feeling of being both suppressed by and inferior to England, and moreover that of being a minority within Great Britain. It was shown that Bligh tries to re-establish the presupposed superior-inferior relationship between England and Cornwall by means of attacking English (high) culture. However, these attacks can be valued as merely rhetorical because the old England-Cornwall relation in which Cornwall is perceived as inferior prevails to be a deeply ingrained part of Cornish identity. This can best be depicted by one of Bligh's final remark which reveals a crucial, if not the most crucial element of Cornish identity: when he speaks about the 'belongingness' to Cornwall explicitly, he declares that if one is truly Cornish, if taking it really on to oneself, one makes oneself a minority within Britain. This underlying notion of being a minority is part of Cornishness in the form of another meta-element. On the one hand the belief that Cornwall is suppressed by England is thus obviously regarded as negative and entails a strong differentiation and enhancement of Cornishness from Cornwall's supporters; but on the other hand, the feeling of being a suppressed minority is an underlying sine qua non of Cornish identity without which it cannot be sufficiently described and understood. 


\section{Comparing Theory and Reality}

The following chapter will deal with this paper's second objective. It aims at identifying the representational strategies through which a Cornish nation is imagined; in this fashion it will combine Hall's theory of identity as depicted in chapter 2 and the analysis of empirical material of Cornish identity from the previous one. I will then examine how a Cornish nation is imagined in terms of the five representational strategies suggested by Hall. Here two limitations will surface: their limited applicability and their incompleteness; these will be discussed in further detail in chapter 4.7. Hall's theory of how nations are imagined will be refined and improved. But before actually applying theory to empirical data, one problem has to be addressed, which is that Hall describes how to imagine a nation although Cornwall is, in terms of its legal status, no nation at all.

\subsection{Cornwall - A Nation?}

Because Hall's five representational strategies originally refer to the way how nations are imagined, it briefly has to be explained why this concept was chosen in order to analyse Cornish identity although Cornwall legally is not a nation in its own right but a county of England. Therefore Anderson's claim that all nations are imagined communities is crucial. Ensuing from this assumption a nation never evolved out of a primordial people and subsequently possesses some sort of legitimacy to be a nation but is always a construct of the human mind, no matter if it is or is not politically acknowledged. To put it in other words, a community of "the same" people which live in a clearly limited geographical area and which identify themselves as sovereign occupants of this territory can be imagined as a nation but this imagination must not be shared by others or does not have to be mirrored by political reality in order to actually define it as a nation. In addition both interviewees clearly related national characteristics to Cornwall (e.g. when Morris defines Cornish identity to be a "national identity" or when Bligh describes wrestling and hurling as the two "Cornish national sports"). Hence the application of Hall's five representational strategies of imagining a nation is justified.

\subsection{Category 1 - Nation as Narration}

Hall suggests narratives of the nation as the first representational strategy through which nations in general are imagined. They represent the "shared experiences" (Hall, "Question of Cultural Identity" 293) of the nation and, as members of this nation, they create that sense of belonging to and being a part of it. Although Morris' construct of Cornish national identity reveals one instance of a national narrative, it does not seem to actually hold significance when it comes to the imagination of a Cornish nation. 
The first and simultaneously only prominent instance when she refers to such a narration is when she talks about the Cornish rebellion of 1497 . Here she reflects on this particular historical event with reference to the actual problem of representation: She claims that "in modernity, we put our own slant on things" and that the Cornish rebellion with its Cornish soldiers is therefore seen by some as "the last non-English army to reach London", by others as a mere "internal rebellion". Because "it is so easy to put modern perceptions onto what happened" in the past, this strategy is only marginally pursued.

Unlike Morris, Bligh concentrates on national narrations rather extensively. However, it has to be said that his interview took twice as long as the one with Morris which could explain the reason for the latter talking in more width and depth about Cornishness and the Cornish nation. Moreover, he was particularly asked to elaborate on Cornish history when Morris was not. Thus the previous analysis of Bligh's construct of Cornish identity has revealed several instances of national narrations which appear to hold significance for him insofar as they suture him into a Cornish imagined community. As far as stories are concerned, he refers to Cornish literature and the Nirex story which are both told either to show Cornish difference from England or Cornish superiority - or better, Cornish noninferiority in comparison to England. Besides it is important for Bligh that Cornwall has a distinct landscape which appears to be rather rural. Coming to historical events he mentions six in more detail: The invasion of the Danes and Vikings, Cornwall becoming a Duchy in 1337, the rebellion led by An Gof in 1497, the Prayer Book Rebellion in 1549, the English Civil War in 1640 and Cornwall becoming am official Celtic nation in 1904. Finally Bligh indirectly refers to national symbols when he talks about Celtic crosses and Carvings which can be found in Cornwall. Although these are primarily Celtic elements of Cornwall, it can be argued that they also are national symbols because for him, Cornwall is primarily seen as a Celtic nation through the Celtic language. To conclude, when Morris does not concentrate on national narratives but recognises the problem of representation in general, Bligh is more prone to use this representational strategy.

\subsection{Category 2 - National Identity as Primordial}

The second representational strategy is that of stressing a nation's "origins, continuity, traditions and timelessness" ("Question of Cultural Identity" 294) through which it is perceived as still being connected to a primordial past which reveals the essential character of a nation. Morris' construct of Cornish identity clearly reveals several instances when she applies this representational strategy. As far as the notion of origin is concerned, she states that Cornwall clearly has different national origins than England. In saying that the Cornish nation today descends from 
the nation of people which originally used to live in Cornwall, she constructs that notion of timelessness which links today's Cornish nation to that of the past.

Next Morris is of the opinion that "Cornish identity [is] a continuity within Cornwall". According to her this is mainly because the Cornish language survived into the nineteenth century, handing over this identity and the traditions that go with it from one generation to the next. Although it died out in the course of the nineteenth century, its revival kept these traditions and Cornish identity alive until today. Moreover it was mentioned that Morris actually is in favour of an elaborate view on history implying that the Anglo-Saxons did not hunt and kill the Celts after having arrived on the island but that they rather governed them. In following this logic Morris claims that the Celtic people still exist today in "all the people of Britain". This reasoning again brings about the notion of a certain continuity; however this time not exclusively with focusing on Cornwall but on Britain as a whole. Morris' elaborate view on history therefore reveals an important characteristic of Cornish national identity which was already discovered above: the fact that it sees Britain as an umbrella term which includes Cornwall, England, Wales and Scotland as "constituent nations" and that hence being British was, and still is, a part of being Cornish. Lastly a distinctive set of Cornish traditions is identified which she unfortunately does not elaborate.

Bligh's construct of Cornish identity also reveals certain instances representing Cornwall's continuous existence over time. To start out with he states that gig rowing and wrestling are two national Cornish sports. Although he does not explicitly refer to the fact that wrestling or gig rowing have been practised in Cornwall for a very long time, he nevertheless identifies them as a "peculiar Cornish thing". Thus he implies that it has been Cornish in a long time. They can be treated as an essentially Cornish tradition underpinning the idea that the origins of a Cornish national identity and a Cornish nation reach a long way back into the past and that the nexus between a past and present Cornish nation is still being maintained. As another instance figures Bligh's representation of the Cornish legal system as a prominent example of Cornish continuity since it is illustrated as both being old - he claims that the Cornish legal system was introduced when Cornwall became a Duchy in 1337 - and still valid today: the Nirex story depicts this most vividly. A more subtle but simultaneously important example supporting the idea of timelessness can be found when having a closer look at the relation between England and Cornwall: the analysis in chapter 3 has revealed that a major element of Cornish identity is the feeling of being suppressed by England, both linguistically and culturally. According to Bligh, Cornwall and other Celtic nations alike have been suffering from this suppression for "thousands of years" and it thus seems to be an essential element now and then.

In terms of his second strategy, Hall claims that people can refer to the past in order to restore an essential national identity. As far as Morris is concerned, she bears upon the past not so much as to restore Cornish identity but rather the 
Cornish status within Great Britain, i.e. that of a more independent nation. Bligh, with attempting to bring the Cornish language back into schools, seems to be more interested in actually strengthening the Celtic Cornish identity by means of referring to the past. Thus where Morris' interest is primarily a political one, Bligh's is rather cultural.

\subsection{Category 3 - Invention of Tradition}

According to Hall a third representational strategy is that of invented traditions. When it comes to Morris, it could be examined in how far Cornish hurling and wrestling are invented traditions. However, this has to be postponed to further researches because of this paper's time restrictions. More assertions can nevertheless be made about Cornish traditions mentioned by Bligh: an examination reveals that the Cornish Gorseth and Cornish bagpipes are two examples of invented traditions. As far as the Gorseth is concerned, Bligh himself is aware of the fact that it has not been existing without interruptions but that it was "reconstructed", such as the Welsh and the Breton also were. Now the term "reconstruction" obviously implies that the Cornish Gorseth used to exist in the remote past and then ceased to exist for unknown reasons; only than could it have been reconstructed. However, the new Cornish Gorseth is not the reanimated form of the ancient one but was introduced from other countries which are perceived as Celtic; thus it can be said that the reconstruction of the Cornish Gorseth is not about a "Wiederbelebung vorgeblich autochthoner kornischer [...] Traditionen" but rather about the "keltischen Symbolcharakter, die [invented traditions] als Inbegriff eines als 'keltisch' etablierten Landes auf Cornwall übertragen“" (Tschirschky 204). The same holds true for Cornish bagpipes which are additionally represented as a Celtic artefact of Cornish culture. Tschirschky claims that bagpipes used to be popular instruments in rural Scotland. With the reinterpretation of Scotland to a Celtic nation in the course of Romanticism, the bagpipe became a symbol of Celticism which could subsequently be used by other nations to represent their Celtic origins; this is exactly what happened in Cornwall (Tschirschky 207f). In this way it can be summarised that invented traditions hold significance at least for Bligh. Because of the complexity of this representational strategy, more time can be spent on examining its actual significance.

\subsection{Category 4 - The Foundational Myth}

The fourth representational strategy is the foundational myth. This particular national narrative contains the story of a nation's origin that can be situated in a past which is so long ago that it actually seemed to have happened "not [in] 'real', but 'mythic' time" (Hall, "Question of Cultural Identity” 294f). When examining Mor- 
ris' construct of a Cornish nation, it becomes clear that she perceives the event when "the Saxons [came] charging across" as one crucial instance of Cornish history although she is of the opinion that the Saxons only ruled, not massacred, the former Celtic inhabitants of the isle. However, this event only appears to be the introduction to an actual foundational myth because she does not mention a "birth" of the Cornish nation before that day when the Saxons came. Further she claims that despite the fact that "we [Cornwall] got sucked [into England] at a very early stage", a separation between England and Cornwall existed for a long time which can be illustrated, for example, by means of a map showing that "Anglia et Cornubia" are separated by a clear demarcation line. Tschirschky claims that "bis in die Tudorzeit wurden viele Rechtsdokumente [...] mit dem Geltungsbereich 'Anglia et Cornubia' ausgestellt" (82f). However, a distinct narration of the birth of the Cornish nation cannot be clearly identified by means of Morris' illustration. A possible interpretation of the lack of this narration within her construction can be twofold: it could not have been triggered by the questions of the interview guideline or she consciously or unconsciously favours different representational strategies. When it comes to Bligh, the case is somewhat clearer. Here the Celtic origins of Cornwall can be interpreted as the Cornish foundational myth: Because Cornwall is perceived as a Celtic country, it is part of the family of the Celtic nations; this is where it comes from.

In sum Bligh's case partly displays Hall's predicted behaviour of "disenfranchised people" (Hall, "Question of Cultural Identity" 294f) using the foundational myth in order to form a new nation. The only difference is that Bligh does not use this representational strategy in pursuance of forming a new nation; for him, the Cornish nation already exists although it might not be legally acknowledged. The foundational myth grants Cornwall this national status in the present: it already is a Celtic nation because it is part of the Celtic family. In contrast Morris does not use this strategy although she is interested in Cornwall becoming admittedly not a nation but at least a devolved part of England. In this fashion she prefers representing Cornwall as possessing the same amount of "otherness" to England than Wales or Scotland without highlighting their proclaimed common Celtic origin.

\subsection{Category 5 - The Original Folk}

The final representational strategy Hall identifies is that a nation is based on the idea of "a pure, original people or "folk" ("Question of Cultural Identity" 295). Morris seems to agree with this notion on the surface when claiming that Cornwall descends from the nation of people which originally existed in Cornwall and that history and Cornish national origins in general identify the Cornish "as a distinct people"; moreover she claims that within the simple view of history, the Cornish descend from the Celts (and the English from the Saxons). Nevertheless, the fact that Morris is in favour of the elaborate view on history weakens her 
agreement with the equation Cornish people $=$ Celtic people because she argues that the Celtic inhabitants were not killed or driven to the west but continued to live on all over what today is Great Britain, entailing that the Saxons and Celts intermingled and not stayed what Hall referred to as "pure".

Bligh makes clear that Cornwall is a Celtic country and that an "essential part of being Cornish is being Celtic". However, he does not immediately determine that Cornwall is Celtic because it is one of the Celtic peoples, but Cornwall is Celtic primarily because of the language. Thus he implies the notion that Cornwall and its people derive from that "Celtic area of culture" which was spread all over Europe in a not further specified past.

In brief, it was found that both Morris and Bligh refer to the idea of Cornish people being Celtic people. Morris, however, only relates to Cornish people as Celtic within her "simple view on history" but rejects it for herself. She favours the idea that the Celts intermingled with the Saxons after the latter's arrival. Bligh in contrast more clearly is convinced that Cornish people are truly Celtic.

\subsection{Refining Hall: Discussion and Additional Representational Strategies from Empirical Evidence}

It was shown that Hall's five representational strategies can be used as categories to analyse how the Cornish nation is imagined. Nevertheless, two weaknesses were brought to the surface: Firstly representational strategies in parts are not significant within the examined cases, and secondly, they do not sufficiently describe the mechanisms of imagining Cornwall as a nation. Thus four more representational strategies could be identified through the analysis of the material: imagining the Cornish nation through language, as being limited, as possessing legitimate authority within its borders, and as being culturally superior. When firstly examining the applicability of Hall's concept, the following table illustrates its limitations:

Tab. 1: Significance of Representational Strategies (Hall's Categories)

\begin{tabular}{|ll|c|c|}
\hline & Morris & Bligh \\
\hline 1. & Nation as Narration & $\sim$ & $\checkmark$ \\
\hline 2. $\quad$ Continuity & $\checkmark$ & $\checkmark$ \\
\hline 3. Invented Traditions & ? & $\checkmark$ \\
\hline 4. Foundational Myth & X & $\checkmark$ \\
\hline 5. Pure Folk & $\sim$ & $\checkmark$ \\
\hline $\begin{array}{l}\checkmark \text { significant } \sim \text { significant with restrictions } \\
\text { ? not examined X insignificant }\end{array}$ \\
\hline
\end{tabular}


Morris' case obviously shows some problems within Hall's theory. The only instance when she is sufficiently in accordance with Hall is in the second representational strategy. As far as the first and last strategy are concerned, at least some overlapping can be identified. When it comes to the foundational myth, the material does not contain any clear clue from which it could be induced. Invented traditions can be suspected to hold at least some degree of significance but their actual applicability has to remain open due to research pragmatics. Bligh in contrast seems to be a rather classic case. Here each strategy can sufficiently be identified in the material under examination.

The analysis of Morris' and Bligh's construct of Cornish national identity has revealed four new representational strategies. The first and simultaneously most important one which cannot be subsumed under Hall's given strategies is the Cornish language. Since the preceding analysis found it to be a prominent factor of Cornishness in both cases under consideration, it can be evaluated as a primary means through which the Cornish nation is imagined. Thus Morris perceives Cornish as "the number one thing for Cornish identity". The distinctive Cornish language moreover provides the very basis for the assumption that it is a national identity and that therefore Cornwall is a nation. Lastly language in general is seen as that necessary "bit of otherness" which facilitates the perception of a nation as being a distinctive entity in contrast to other nations. In the case of Bligh, it becomes additionally obvious that language "is a key to it all" and a major means of imagining Cornwall as a nation. In this way language is perceived at the core of Cornish national identity from which other Cornish elements derive, e.g. Cornish traditions. The fact that Cornwall was permitted as one of the six Celtic nations is exclusively due to the fact that Cornish is a Celtic language. Finally the analysis in chapter 3 has revealed that Bligh is of the opinion that Cornish as a language makes Cornwall a nation, just as England and Wales are nations, too. For the sake of completeness, it must be stated that Hall also reflects the importance of language within cultural identities. However, he does not single out the feature which is the claim which is made here - but places linguistic culture next to ethnic, religious, or national culture which generally are points of reference for cultural identity (cf. Hall, "Question of Cultural Identity" 274); he does not explicitly identify language as a further representational strategy which clearly has to be done after the analysis of the given material.

The second representational strategy not being taken into consideration by Hall can be borrowed from Anderson: limitedness. This method of imagining the Cornish nation again figures prominently in both cases. In referring to the fact that Cornish was not spoken outside its borders, Morris explicitly bespeaks a geographical limitedness of the Cornish nation expressed through language. In stating that Cornish rules for wrestling are not compatible with the Devon counterparts, she furthermore underpins not only the notion of difference but also that of limitedness expressed through tradition. When it comes to Bligh, linguistic and tradi- 
tional arguments are additionally found to emphasise the notion that Cornwall is a geographically separate area. Again Hall does include the idea of limitedness within the framework of his theory when claiming that cultural identities evolve around "points of difference" ("Question of Cultural Identity" 227) which entail that these identities have an imagined border and thus are limited; nevertheless, in his works under consideration limitedness refers only to cultural identities and is not identified as a representational strategy.

The third strategy which is not included but significant is that of imagining the nation or its representatives as possessing legitimate authority within its borders. This time it has similarities to Anderson's notion of sovereignty (cf. 7); however, the source of that sovereignty which according to Anderson is the fact that it superseded monarchy becomes only marginally important here. Moreover this strategy can only be identified in Morris' case. She discovers a contradiction between Cornwall's entitlement and reality referring to legislative and executive power: although Cornwall ought to be entitled to "make more decisions locally", Westminster government in fact makes those decisions at the time being. Underlying this is the notion that Cornwall is entitled to self-government because nations as such are sovereign within their territory. When it comes to Hall, he refers to Anderson and starts from the assumption that nations are imagined communities and hence implicitly includes that nations are imagined as limited, sovereign and as a community (cf. Anderson 7; cf. Hall, "Question of Cultural Identity" 254f). However, Hall again does not explicitly include the aspect of legitimate authority as a representative strategy.

Finally the fourth new representational strategy is the imagining of a nation as culturally superior. This figures most prominently in Bligh's construct of a Cornish national identity. In this way he undermines the value of the English language and reduces it to a "noise which comes out of your mouth". In deeming Shakespeare only a second-rate poet and attesting the mere thought of putting him on equal grounds with Cornish high culture to suffer from megalomania, he rather clearly illustrates a certain superiority of Cornish literature compared to the English one. Having said that, it has to be kept in mind that one of the most important aspects of Cornish national identity and thus of imagining the Cornish nation is that of being suppressed and a minority within Great Britain. Therefore, although Cornish cultural superiority could be seen as an expression of its national character, Cornwall must not be acknowledged as a nation in political reality in order not to harm the minority condition of Bligh's Cornish national identity. In sum and after having refined Hall's theory in terms of how to imagine a Cornish nation, the following table includes the induced representational strategies and depict their application in the two respective constructs: 
Tab. 2: Significance of Representational Strategies (Amended List)

\begin{tabular}{|cl|c|c|}
\hline & Morris & Bligh \\
\hline 1. & Nation as Narration & $\sim$ & $\checkmark$ \\
\hline 2. $\quad$ Continuity & $\checkmark$ & $\checkmark$ \\
\hline 3. Invented Traditions & $?$ & $\checkmark$ \\
\hline 4. $\quad$ Foundational Myth & $\mathbf{X}$ & $\checkmark$ \\
\hline 5. 'Pure' Folk & $\sim$ & $\checkmark$ \\
\hline 6. Language & $\checkmark$ & $\checkmark$ \\
\hline 7. Limitedness & $\checkmark$ & $\checkmark$ \\
\hline 8. Legitimate Authority & $\checkmark$ & $\mathbf{X}$ \\
\hline 9. Cultural Superiority & $\mathbf{X}$ & $\checkmark$ \\
\hline $\begin{array}{l}\checkmark \\
\text { significant } \sim \text { significant with restrictions }\end{array}$ \\
\hline
\end{tabular}

\section{Conclusion}

The starting point was the hypothesis that Cornish people perceive themselves as members of a Cornish nation even though Cornwall, in legal terms, is no nation at all. In order to judge whether or not this hypothesis is admissible, two objectives determined the concept of this paper: Firstly the examination of two types of Cornish identity ought to reveal if Cornish people themselves in fact perceive themselves as members of a Cornish nation; secondly, because nations are imagined communities, the way of how the Cornish nation is imagined by Cornish people was explored. The analysis of two interviews in chapter 3 has revealed two different types of Cornish identity which evidently included both the notion of being different from and not subsumable under an English identity and explicitly referred to Cornwall as a nation in its own right, not a region or a county which the legal status would imply. Although the reasons for Cornish difference varied between the two types, both of them refer to the fundamental Cornish difference from England and the Cornish language as major justifications for calling Cornwall a nation. Chapter 4 subsequently explored the way in which this Cornish nation is imagined by means of Stuart Hall's representational strategies of how nations are imagined in general. It was found that the type of Cornish identity represented by Keneder Bligh matches well with Hall's suggested strategies; with reference to the type represented by Eve Morris, in contrast, the application of some categories was problematic. Moreover it was found that Stuart Hall's concept of imagining a nation in the cases under consideration was sometimes not significant or sufficient and hence needed refinement. 
Although the analysis in chapter 4 was mainly dedicated to the second objective and thus with the question of how a Cornish nation is imagined, it could be understood as a means of validation for the previous claim that Cornwall is perceived as a nation through the eyes of the Cornish. In this fashion Hall's five strategies could be perceived as criteria testing whether or not a community is in fact imagined as a nation. Hence Bligh's type could be clearly defined as presupposing a Cornish nation because all of the five strategies were found to be followed; the claim made in chapter 3 would be underpinned by the analysis of chapter 4 (cf. table 1). In contrast, Morris' case does not as clearly figure as an example of a type of Cornish identity presupposing a Cornish nation because she does not include all five strategies suggested by Hall; the previous claim of chapter 3 that Morris' concept includes the notion of a Cornish nation would be at least weakened when tested by the five strategies. However, the applicability of Hall's strategies as a general means of further exploring this paper's hypothesis can be challenged for mainly two reasons: firstly, although the type of Cornish identity Morris represents does not completely match with these strategies, other representational strategies, first of all the Cornish language, are found in her as well as in Bligh's construct. This could entail that Hall's concept of how to imagine a nation is not complete and thus could not be used as a test of validation. It secondly is most likely that during the stage of data collection not all the data was ascertained and that some representational strategies were not collected. It is thus finally claimed that the hypothesis could not be falsified in the course of the paper: The first analysis has revealed that the Cornish under consideration describe themselves as members of a nation and possess a national identity which is significantly distinct from the English national identity.

However, the admissibility of the hypothesis must be limited. It was not falsified only with regards to the two types of Cornish identity in question from which no general statement about the construct of Cornish identity in general can be drawn: for this more interviews with a variety of people would have to be conducted in order to generate a more general construct of Cornish identity. Furthermore it must be kept in mind that the interview partners were selected in terms of their virtual visibility: only those could be found during internet research in the first stage of data collection which were visible on the internet because they were affiliated to organisations trying to support Cornish identity or Cornish culture. In addition, no detailed links, neither asynchronous nor diachronic, between the Cornish legal situation defining Cornwall as a county and the self-description of (some) Cornish people of Cornwall as a nation can be offered; neither the history of Cornwall's legal status compared to Cornish identity over time can hence be explored, nor can the Cornish political agitation, grounding on the notion that Cornwall is a nation, towards the legal situation be examined.

The illustrated limitations can be seen as invitations for future research. On the basis of this thesis' findings, it could be analysed in how far the representa- 
tions of Cornish history - especially those given by Keneder Bligh - coincide with actual historical sources; and if they do not it could be examined whether particular representations of historical facts serve political, cultural, or other ends. In a broader context a more complex and universal construct of Cornish identity could be acquired by means of more extensive empirical and literary research. As far as future interview partners are concerned, it has to be made sure that a varied or random sample is selected in order not to influence the results because of the study design. Lastly another method of data collection and data analysis could be preferred which asserts the claim of being more inductive than Mayring's content analysis such as the before mentioned approach of Rosenthal.

In a broader sense the results can be related to the theoretical concept of nation and the discourse evolving around Cornish nation building. Thus it was shown that the scientific category of nation has to be understood according to Anderson's notion of it as an "imagined community": the legal acknowledgement of a community as a nation is in fact no necessary condition of a community to be perceived as a nation, for example through the eyes of some of its members. Furthermore, two instances or types of Cornish national identity were identified in which the aspect of Cornish nationality figures prominently; these types could be examined further in the field of Cornish Studies concentrating on nation-building processes within Cornwall. ${ }^{4}$

After the analysis it can be concluded that neither Walter White's impressions of the 1850s, nor the everyday experiences in today's Cornwall came and come out of thin air. Indeed, back then as well as today, it appears that at least some Cornish people have not get acquainted with the fact that they ought to be English. Whether or not this will finally lead to a legally acknowledged Cornish nation, separate from England, only time will tell. Thus, it remains exciting.

\section{Bibliography}

Anderson, Benedict. Imagined Communities: Reflections on the Origin and Spread of $\mathrm{Na}$ tionalism. Rev. ed. London: Verso, 2006. Print.

Barker, Chris, and Paul Willis. Cultural Studies: Theory and Practice. Los Angeles: SAGE Publ, 2009. Print.

Bligh, Keneder. Interview by Benjamin Schlink. 3 Jun. 2013.

"culture." OED Online. March 2008. Oxford University Press. Web. 11 June 2013.

4 For an introduction into this field of research, Tschirschky's "Die Erfindung der keltischen Nation Cornwall" is a good starting point. 
“essence.” OED Online. Oxford University Press. Web. 15 July 2013.

Flick, Uwe, Ernst v. Kardorff, and Ines Steinke. Qualitative Forschung: Ein Handbuch. Orig.-Ausg., Reinbek bei Hamburg: Rowohlt, 2007. Print.

Hall, Stuart. "Cultural Identity and Diaspora." Theorizing Diaspora: a Reader. Ed. Jana Evans Braziel, and Anita Mannur. Malden, Mass.: Blackwell, 2003. 23346. Print.

-: "The Question of Cultural Identity." Modernity and Its Futures. Ed. Stuart Hall, David Held, and Tony McGrew. Cambridge, UK: Polity Press, 1993, 273326. Print.

—: "Introduction: Who needs Identity?" Questions of Cultural Identity. Ed. Hall, Stuart, and Paul Du Gay. Los Angeles: Sage, 1996. 1-17. Print.

Hall, Stuart, and Sut Jhally, eds. Representation and the Media. Northampton, MA: Media Education Foundation, 1997. DVD.

Hobsbawm, Eric, ed. The Invention of Tradition. Cambridge: Cambridge Univ. Press, 1983. Print.

Kant, Immanuel. "Was ist Aufklärung?” Berlinische Monatsschrift 12 (1784): 481-94. Web. 26 Jul. 2013.

Mayring, Philipp. Qualitative Inhaltsanalyse: Grundlagen und Techniken. Weinheim: Beltz, 2007. Print.

Morris, Eve. Interview by Benjamin Schlink. 31 May 2013.

Nünning, Ansgar. Metzler's Lexikon Kultur-und Literaturtheorie: Ansätze - Personen Grundbegriffe, Stuttgart: Metzler, 2008.

Rosenthal, Gabriele. Interpretative Sozialforschung: Eine Einfübrung. Weinheim: Juventa-Verl, 2011. Print.

Rowse, Alfred L. Tudor Cornwall: Portrait of a Society. London: Cape, 1957. Print. Bedford Historical Studies.

Tschirschky, Malte. Die Erfindung der keltischen Nation Cornwall: Kultur, Identität und ethnischer Nationalismus in der britischen Peripherie. Heidelberg: Universitätsverlag Winter, 2006. Print.

White, Walter. A Londoner's Walk to the Land's End, by Walter White. 2nd. London: Chapman \& Hall, 1861. Print. 